\title{
Evaluation of a serological test for tuberculosis
}

\author{
D A MITCHISON, V R ABER, F J AHMAD, B W ALLEN, S DEVI
}

British Medical fournal, 1977, 1, 1383-1387

\section{Summary}

The agglutination test of Nicholls was found to be ineffective in diagnosing active tuberculosis. A positive result (titre of $1 / 125$ or more) was found in the serum of $74(70 \%)$ out of 105 patients with newly diagnosed, smearpositive pulmonary tuberculosis; $61(62 \%)$ out of 98 healthy family contacts; and $19(63 \%)$ out of 30 patients with non-tuberculous conditions. These findings were not due to faulty technique since the results obtained at Hammersmith were similar to those obtained by Nicholls's laboratory in the same serum samples. Twenty-seven of the tuberculous patients who had a negative result before treatment were retested two months after the start of chemotherapy but showed no evidence of a rising titre.

\section{Introduction}

Since the first description of a serological test for tuberculosis by Middlebrook and Dubos in $1948,{ }^{1}$ several attempts have been made to develop a technique which would discriminate efficiently between patients with active disease and those who have inactive disease or have never been infected with Mycobacterium tuberculosis. ${ }^{2-9}$ Nicholls has recently described a simple agglutination test based on the empirical observation that treatment of a suspension of $M$ tuberculosis with sodium hydroxide prevents autoagglutination of the organisms. ${ }^{10}$ This test was claimed to be highly specific, a positive result being obtained in 59 out of 63 patients with culture-positive tuberculosis but in only three out of 171 patients with other diseases. In a later report positive results were found in 57 out of 68 patients with tuberculosis and nine out of 154 patients with other conditions. ${ }^{11}$ Among the 11 tuberculous patients with negative serological findings were seven who subsequently gave a positive result. In view of the wide interest engendered by these promising results, we have attempted, but without success, to repeat the findings.

\section{Methods}

We tested five groups of sera. Sera were taken from: 40 patients at Hammersmith Hospital suffering from various diseases, including tuberculosis (group 1); 105 patients in Singapore with newly diagnosed, smear-positive, pulmonary tuberculosis who had been admitted to a study of intermittent treatment with isoniazid and rifampicin ${ }^{12}$ (group 2); 98 family contacts of the patients in Singapore (group 3); 30 British patients who were unlikely to have had active tuberculosis and who were being screened for evidence of syphilis (group 4); and

27 patients whose pretreatment sera (group 2) had shown low titres and who were tested again after two months' of chemotherapy (group 5).

Sera from group 1 had already been sent to Midhurst for routine testing by Dr Nicholls as an aid to diagnosis. The 98 family contacts who provided group 3 sera all had chest radiographs taken within seven days of blood collection and 97 also underwent a Mantoux test with 1 TU purified protein derivative RT23 at the same time. A repeat radiograph was obtained in 76 of these people four to 12 months later. All radiographs were normal.

Sera from Singapore were flown frozen to Hammersmith. All sera at Hammersmith were stored at $-20^{\circ} \mathrm{C}$. The agglutination tests were carried out as described by Nicholls, ${ }^{10}$ who provided the antigen suspensions used. All of the tests were read by observer 1 , whose results are presented throughout, and most by observer 2 also. The origin of the sera was not disclosed to the observer until after the tests had been read.

\section{Results}

The results in group 1 sera, tested in several batches at Midhurst and Hammersmith (table I), agreed fairly well (correlation coefficient, $r=0.64)$. As might have been expected, observer 1 and observer 2 agreed more closely in their readings (not tabulated here) of the same test on 190 sera at Hammersmith $(r=0.85)$.

TABLE I-Comparison of agglutination test results at Hammersmith and Midhurst on group 1 sera

\begin{tabular}{|c|c|c|c|c|c|c|}
\hline \multirow{2}{*}{$\underset{\text { titre }}{\text { Midhurst }}$} & \multicolumn{5}{|c|}{ Hammersmith titre } & \multirow{2}{*}{ Total } \\
\hline & $<25$ & 25 & 50 & 125 & $\geqslant 250$ & \\
\hline $\begin{array}{r}<25 \\
25 \\
50 \\
125 \\
250 \\
\geqslant 500\end{array}$ & $\begin{array}{l}1 \\
1 \\
3\end{array}$ & $\begin{array}{l}2 \\
5 \\
1 \\
1\end{array}$ & $\begin{array}{l}6 \\
1 \\
2\end{array}$ & $\begin{array}{l}2 \\
3 \\
4\end{array}$ & $\begin{array}{l}1 \\
4 \\
3\end{array}$ & $\begin{array}{r}1 \\
3 \\
17 \\
5 \\
11 \\
3\end{array}$ \\
\hline Total & 5 & 9 & 9 & 9 & 8 & 40 \\
\hline
\end{tabular}

At Hammersmith we compared the results in groups 2, 3, and 4 (table II). A positive result, with a titre of $1 / 125$ or more, was obtained in sera from $74(70 \%)$ of the 105 patients with active tuberculosis (group 2), $61(62 \%$ ) of the 98 contacts in group 3 , and $19(63 \%)$ of the 30 British controls in group 4. In group 3, no association was found between test results and the Mantoux reaction or previous BCG vaccination. Thus a positive serological result was found in $16(84 \%)$ out of 19 contacts with negative Mantoux reactions (induration < $5 \mathrm{~mm}$ diameter) and in $46(59 \%)$ out of 78 contacts with positive reactions $(P=0.08)$. Positive results were also obtained in $44(62 \%)$ of the 71 contacts who had previously been vaccinated with BCG and in $19(70 \%)$ of the 27 unvaccinated contacts.

TABLE II-Agglutination test results on tuberculous and non-tuberculous subjects

MRC Unit for Laboratory Studies of Tuberculosis and Department of Bacteriology, Royal Postgraduate Medical School, London W12 0HS

D A MITCHISON, FRCP, FRCPATH, director

V R ABER, MSc, DIC, member of MRC scientific staff

F J AHMAD, MB, DCP, registrar

B W ALLEN, FIMLS, MBIOL, chief technician

Outpatient Services, Singapore 2

S DEVI, MB, FRCP, medical superintendant

\begin{tabular}{|c|c|c|c|c|c|c|}
\hline \multirow{2}{*}{ Titre } & \multicolumn{2}{|c|}{$\begin{array}{l}\text { Group } 2 \\
\text { TB patients }\end{array}$} & \multicolumn{2}{|c|}{$\begin{array}{c}\text { Group } 3 \\
\text { Healthy contracts }\end{array}$} & \multicolumn{2}{|c|}{$\begin{array}{c}\text { Group } 4 \\
\text { Non-tuberculous }\end{array}$} \\
\hline & No & 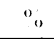 & No & $\%$ & No & $\%$ \\
\hline $\begin{array}{r}\leqslant 25 \\
50 \\
125 \\
2250\end{array}$ & $\begin{array}{l}11 \\
20 \\
39 \\
35\end{array}$ & $\begin{array}{l}11 \\
19 \\
37 \\
33\end{array}$ & $\begin{array}{l}15 \\
22 \\
28 \\
33\end{array}$ & $\begin{array}{l}15 \\
22 \\
29 \\
34\end{array}$ & $\begin{array}{r}3 \\
8 \\
12 \\
7\end{array}$ & $\begin{array}{l}10 \\
27 \\
40 \\
23\end{array}$ \\
\hline Total & 105 & 100 & 98 & 100 & 30 & 100 \\
\hline
\end{tabular}


Since the technique of testing at Hammersmith might have been at fault, we selected 44 sera from those available in sufficient volumes to be retested at Midhurst. The batch included equal proportions of sera from the presumptively positive group 2 and the presumptively negative groups 3 and 4 chosen so that there would be similar proportions of those found to be positive or negative in the Hammersmith tests. These sera were sent coded to Midhurst. Of the 22 group 2 sera from tuberculous patients 11 were positive $(>1 / 125)$ at Hammersmith and eight were positive $(\geqslant 1 / 120)$ at Midhurst. Of the 22 sera in groups 3 and 4 from contacts and controls eight were positive at Hammersmith and nine at Midhurst. For the entire comparison $r=0.54$; the results obtained at Hammersmith and Midhurst agreed as positive or negative for 38 of the 44 sera. Thus the failure of the Hammersmith tests to distinguish between group 2 and groups 3 and 4 could not be attributed to differences in the methods used in the two laboratories.

TABLE III-Agglutination test results on sera obtained before treatment and two months later from tuberculous patients

\begin{tabular}{|c|c|c|c|c|}
\hline \multirow{2}{*}{$\begin{array}{l}\text { 2-Month } \\
\text { titre }\end{array}$} & \multicolumn{3}{|c|}{ Pretreatment titre } & \multirow{2}{*}{ Tota } \\
\hline & 25 & 50 & 125 & \\
\hline $\begin{array}{r}\leqslant 25 \\
50 \\
\end{array}$ & $\begin{array}{l}7 \\
6 \\
\end{array}$ & $\begin{array}{l}5 \\
7\end{array}$ & 2 & $\begin{array}{l}12 \\
15\end{array}$ \\
\hline Total & 13 & 12 & 2 & 27 \\
\hline
\end{tabular}

In view of the claim that occasional patients with culture-positive tuberculosis might have an initial low titre in the test followed a few weeks later by a diagnostic rising titre, ${ }^{11}$ tests were carried out on group 5 sera, which were samples obtained two months after the start of chemotherapy from 27 patients whose pretreatment sera had low titres (group 2) (table III). There was no evidence of any change during the period: a titre of 50 or more was obtained in 14 pretreatment sera and in 15 taken at two months.

\section{Comment}

The similarity of the results of the agglutination test in patients with active pulmonary tuberculosis; in healthy contacts, whether or not they were positive on the Mantoux test; and in patients with non-tuberculous conditions indicates that the test has no value in diagnosing active tuberculosis and should not be requested for this purpose. This failure to confirm the claims from the Midhurst Medical Research Institute does not seem to be due to differences in the method used in the two laboratories since the results obtained at Midhurst and Hammersmith agreed reasonably well. In particular, the Midhurst laboratory found a similar number of negative results among the sera from patients with active tuberculosis and positive results among sera from the non-tuberculous controls.

\section{References}

${ }^{1}$ Middlebrook, G, and Dubos, R J, fournal of Experimental Medicine, 1948, 88, 521.

2 Parlett, R C, and Youmans, G P, American Review of Respiratory Disease, 1959, 80, 153.

3 Takahashi, Y, American Review of Respiratory Disease, 1962, 85, 708.

4 Wallace, R, et al, Canadian Medical fournal, 1966, 94, 947.

${ }^{5}$ Duboczy, B O, and White, F C, American Review of Respiratory Disease, 1966, 94, 914.

${ }^{6}$ Cole, R V, Lazarus, A W, and Hedrick, H G, Applied Microbiology, 1972, 24, 525.

7 Affronti, L F, Fife, E H, and Grow, L, American Review of Respiratory Disease, 1973, 107, 822

${ }^{8}$ Nassau, E, Parsons, E R, and Johnson, G D, Fournal of Immunological Methods, 1975, 6, 261.

${ }^{9}$ Reggiardo, Z, and Middlebrook, G, American fournal of Epidemiology, 1975, 100, 477 .

${ }^{10}$ Nicholls, A C, Journal of Clinical Pathology, 1975, 28, 850.

11 Nicholls, A C, and Horsfield, K, Thorax, 1976, 31, 289.

12 Singapore Tuberculosis Service-British Medical Research Council, Lancet, 1975, 2, 1105.

\title{
Antipyrine, paracetamol, and lignocaine elimination in chronic liver disease
}

\author{
JOHN A H FORREST, N D C FINLAYSON， K K ADJEPON-YAMOAH， L F PRESCOTT
}

British Medical fournal, 1977, 1, 1384-1387

\section{Summary}

The plasma half lives of antipyrine, paracetamol, and lignocaine given by mouth were measured in 23 patients with stable chronic liver diseases of varying severity. Fifteen patients received all three drugs and 19 at least

\section{Gastrointestinal and Liver Service, Royal Infirmary, Edinburgh EH3 9YW}

JOHN A H FORREST, BSC, MRCP, senior registrar in gastroenterology N D C FINLAYSON, PHD, MRCP, consultant physician

University Department of Therapeutics, Royal Infirmary, Edinburgh EH3 9YW

K K ADJEPON-YAMOAH, PHD, MRCP, research fellow in clinical pharmacology (present address: Department of Pharmacology, University of Ghana Medical School, Accra, Ghana)

L F PRESCOTT, MD, FRCPED, reader in clinical pharmacology and consultant physician two. The half life of paracetamol was abnormally prolonged in nine out of 17 patients (mean 2.9 hours, normal 2.0 hours), of antipyrine in 10 out of 19 patients (mean 30.4 hours, normal 12.0 hours), and of lignocaine in 19 out of 21 patients (mean 6.6 hours, normal 1.4 hours). Prolongation of the half lives of all three drugs was significantly correlated with an increase of the vitamin- $K_{1}$ corrected prothrombin time ratio and a reduction in serum albumin concentration. There was no correlation with serum bilirubin concentration or serum alanine aminotransferase activity. This suggests that impaired drug elimination was related to depressed hepatic protein synthesis. Considerable prolongation of the half life of one drug was invariably associated with delayed elimination of the others. The half life of lignocaine, however, was always the most prolonged and was a highly sensitive indicator of hepatic dysfunction. The pharmacokinetic characteristics of a drug as well as the severity of liver disease should be taken into account when considering drug dosage in patients with chronic liver disease. 